\title{
INCÔMODOS LAÇOS: ESCRITA AFRO-URBANA DA VIOLÊNCIA
}

Adélcio de Sousa Cruz

Doutor em Letras: Literatura Comparada - UFMG e pesquisador do NEIA/UFMG

\begin{abstract}
RESUMO
Este trabalho visa uma breve reflexão comparativa sobre a literatura urbana negra e/ou afrodescendente produzida a partir do contato cotidiano com a violência. Isto será feito a partir do diálogo entre o romance The vulture, de autoria de Gil ScottHeron, e a narrativa de Paulo Lins, Ferréz e Conceição Evaristo.
\end{abstract}

\section{PALAVRAS-CHAVE}

Narrativa afrodescendente, violência, representação, literatura urbana

$$
\begin{array}{r}
\text { Quando o sangue bater em sua porta, } \\
\text { espero que você entenda. }
\end{array}
$$

MV Bill

Tá lá o corpo estendido no chão/ Em vez de um rosto/ Uma foto de um gol/ Em vez de reza uma praga de alguém/ E um silêncio servindo de amém.

Aldir Blanc

O escritor afro-americano Gil Scott-Heron publicou um romance nos anos 1970, The vulture, pouco conhecido no Brasil e que, de certa forma, fazia coro com as narrativas de autores que optaram por uma estética afrodescendente. O tema de seus textos aqui analisados é lido, à primeira vista, simplesmente como representação da violência urbana que afeta de maneira pontual às comunidades relegadas à condição periférica de cidadania. Entretanto, tais narrativas vão, além disso, pois há uma tessitura composta por elementos da cultura negra urbana e que, infelizmente, continuam sem a devida atenção por parte da crítica e dos grandes editores. À exceção de Paulo Lins, os outros dois escritores e a escritora Conceição Evaristo, tratados neste ensaio, não publicam seus primeiros trabalhos a partir de uma grande editora.

Certa ocasião fui indagado por uma estudante de graduação sobre o tom 
“angustiante” e "claustrofóbico" de alguns textos afrobrasileiros. A resposta também não a agradou: afirmei que não eram produzidos a partir do ponto de vista dos autores de novelas televisivas. Tais poemas e narrativas se diferenciavam substancialmente das imagens de negras e negros sorridentes veiculadas pela mídia, por exemplo, em ocasiões como o Carnaval e a Copa do Mundo de Futebol. O intuito dos textos afrobrasileiros é bastante diverso: nada de adormecer o cérebro, o que se pretende é a reflexão sobre o mundo que constantemente sitia o leitor. Nada de alívio, o texto pretende instigar os leitores a buscarem alternativas após cada choque estético... A comunidade afrobrasileira sempre teve o sangue batendo à sua porta, retomando o verso de MV Bill na epígrafe deste texto. É possível encontrar uma pequena amostra disso nos escritos aqui, brevemente, comparados.

O que une autores como os que aqui pretendo analisar? Primeira alternativa seria o fato de criarem suas narrativas a partir do espaço urbano, mas isso os colocaria num grupo mais numeroso e, até mesmo, difuso... Quando dirigimos o olhar para o espaço geográfico transportado para o literário, ainda assim, teríamos uma considerável redução de integrantes. Porém, no momento em que identificamos características das personagens - gênero, etnia, classe social, por exemplo -, aliada ao ponto de vista expresso nas vozes narrativas, podemos perceber outro arranjo estético se destacando: a estética urbana afrodescendente.

Se para Paul Gilroy ${ }^{1}$ há o que ele denominou "Atlântico Negro”, pode-se pensar numa conformação imaginário-espacial que, mesmo se modificando constantemente como ocorre em toda cidade, delineia um modo "outro" de narrar e nomear a urbe. Tal nomeação não ocorre mais, somente, a partir das regiões das quais emana o poder, parte justamente dos “lugares” que o poder utiliza como depositário de subalternidade. Periferia, banlieu, projects, ghetto, favela ${ }^{2}$... Esse ato delibera não mais a anuência do subalterno humilde, do Uncle Thomas ("Pai Tomás”, personagem de romance homônimo que se caracteriza pela subserviência e aceitação passiva da violência da escravidão), do “preto de alma branca”, do “bom-mulato”... Tais narrativas são geradas em tom de automanifestação contra o rótulo, o estereótipo dado e reforçado ora pela imprensa, ora por estudos sociológicos, ora por aparatos do Estado, que possuem o direito exclusivo do uso da violência (mas, infelizmente, não tais instituições apenas,

\footnotetext{
${ }^{1}$ GILROY. The Black Atlantic: modernity and double consciousness.

${ }^{2}$ DAVIS. Planeta favela.
} 
pois há concorrentes mais ferozes, a saber: tráfico de drogas, milícias, grupos de extermínio, etc.), ora pelo quase nunca descompromissado senso comum.

São contra contínuos processos de quase "naturalização”, “normalidade” e uma perigosa tácita aceitação de ligar os moradores da “periferia”, que lutam as narrativas de Gil Scott-Heron, Paulo Lins, Ferréz, Conceição Evaristo. No caso dos textos aqui analisados, todos retratam, em grande parte, a parcela "negra ou mulata, como queiram”. No entanto, o modo de representar tais personagens pretende modificar o rotineiro estatuto das literaturas tout cour: a fixação da subalternidade através do estereótipo. Entretanto, como fazê-lo se a violência parece consumir preciosos espaços na trama e no enredo? De que maneira uma personagem negra que empunha uma arma - criada por estes autores - se diferencia em humanidade daquela apresentada em tantos outros romances e contos? É realmente “outra” impressão estética uma cena como a que segue, na qual o corpo de um jovem negro jaz numa calçada?

The crowd of passerby inched closer to the corpse, trying to get a better look. Here and there women turned their heads and shielded their children's eyes as they noticed for the first time the red ooze that trickled from the base of the skull. ${ }^{3}$

O ponto de vista do narrador inclui a visão interna dos moradores da comunidade - reforçada pela atitude materna da tentativa de proteção dos filhos pequenos. Talvez, pela impossibilidade de impedir que os corpos de jovens continuem a “aparecer” nas calçadas do bairro, essas mães utilizam mãos e o próprio corpo como escudo, preservar a infância... A “multidão de transeuntes” se acerca do cadáver, numa atitude mista de fascínio e repulsa transbordando como o sangue que escapa da base fraturada do crânio. A descrição aglutina diferentes tonalidades textuais: o relatório criminalístico, a coluna da página policial da imprensa, o comentário do sem-número de “curiosos”. A verdade da cena se impõe: apenas as mães parecem se interessar em preservar alguém do horror. A dor e o medo inevitáveis a partir do contato das crianças com a violência estatelada na calçada.

Essa cena irá ecoar nos versos de Aldir Blanc presente na epígrafe... A letra para a música do compositor e intérprete João Bosco, à sua maneira, denuncia a indiferença

\footnotetext{
3 “A multidão de transeuntes se acotovelava cada vez mais próxima ao cadáver, tentando conseguir um melhor ângulo de visão. Aqui e ali havia mulheres que viravam suas cabeças na direção oposta e protegiam os olhos das crianças, assim que notavam o espesso líquido vermelho que lentamente fluía da base do crânio.” (SCOTT-HERON. The vulture, p. 3.) (tradução nossa)
} 
e/ou o medo. Na impossibilidade de fecharem a "janela de frente pro crime”, como faz o eu-lírico criado por Blanc, essas mães transformam momentaneamente o corpo em escudo...

A violência que ronda e percorre as ruas e edifícios da vizinhança em que morava a personagem John Lee é proveniente da mesma fonte que aflige e atinge o espaço narrado por Paulo Lins em Cidade de Deus (1997), Ferréz em Capão pecado (2001), Manual prático do ódio (2003) e Conceição Evaristo em três de seus mais conhecidos contos, a saber, “Maria” (1991), “Ana Davenga” (1998) e "Zaita não guardou os brinquedos” (2007). Refiro-me especificamente ao crime e ao tráfico de drogas.

\section{NARRADORES MASCULINOS...}

Devo registrar de antemão que parte da análise, referente aos textos de Paulo Lins e Ferréz, se encontra também em minha tese de doutorado. ${ }^{4}$ As personagens criadas por Lins e Ferréz em seus respectivos romances vivem num ambiente regido e cerceado pelo crime e pelo tráfico. É curioso notar como esses elementos afetam, mimetizada de maneira capital, a trajetória dos seres de papel. Tanto na fictícia Cidade de Deus ou no Capão Redondo, narrado em Manual prático do ódio (2003), as personagens sucumbem sob o peso das balas de diversos calibres. $\mathrm{O}$ aspecto assustador dessa ficção é sua correspondência quase direta com as estatísticas das vítimas de crimes violentos do mundo real: fator constituinte do que a pesquisadora Regina Dalcastagnè ${ }^{5}$ denomina "vítimas preferenciais", sujeitos pertencentes às camadas mais oprimidas da população que reside nas periferias dos grandes centros urbanos, a saber, negros e/ou não brancos, pobres, mulheres, jovens, crianças e idosos. Veja a seguir como isso ocorre com uma das personagens de Manual prático do ódio (2003), segundo romance do paulistano Ferréz. Em MPO o leitor descobrirá a saga de um grupo de marginais, do qual todos os integrantes desejam fazer a "última correria”: aquela que significasse, de uma vez por todas, a "aposentadoria” da "vida loka”, da vida do crime... A personagem aqui destacada é conhecida por todos como Neguinho da Mancha na Mão.

\footnotetext{
${ }^{4}$ CRUZ. Narrativas contemporâneas da violência: Fernando Bonassi, Paulo Lins e Ferréz.

${ }^{5}$ DALCASTAGNÈ. Estudos de literatura brasileira contemporânea: literatura nas margens; DALCASTAGNÈ. Estudos de literatura brasileira contemporânea: a personagem do romance.
} 
Logo de início, deve-se ressaltar um ponto importante em relação à personagem Neguinho, se comparado a todos que compõem a pequena quadrilha chefiada por Mágico: ele é o único sem lembrança alguma de infância. O jovem apaixonado pela garota Eduarda é apresentado pelo narrador da seguinte maneira: "Neguinho da Mancha na Mão nunca havia passado o dia todo em casa, o revólver na cintura era de praxe, afinal os inimigos não dão aviso prévio...”6 Essa personagem sem memória, sem passado, é colocada na corrente de águas rápidas do enredo tendo uma arma como extensão natural de seu corpo. Os únicos momentos de afetividade são vividos ao lado de Eduarda. O primeiro encontro ocorre na mesma noite em que ele, ao dirigir-se para o bar do Neco, encontra e elimina o assassino de seu primo. A morte de Guile será mais uma sentença a pairar sobre sua cabeça, já que ao final do romance é revelado o verdadeiro elemento motivador do desmantelamento do grupo: o seu parceiro Régis. Neguinho da Mancha na Mão, ou Windsor, seu nome de registro, que só utilizado quando ele estava a sós com Eduarda, tornou-se quase naturalmente a escolha do narrador. Neguinho se vê alvo da escolha de Régis para ser a vítima a ser imolada, aquela que padeceria por todos os males que os rodeavam. Transcrevo a cena final de Neguinho:

Eduarda chorou muito, os pais a seguraram para que não caísse, o caixão estava muito bonito, flores de todas as cores, o enterro de Windsor estava cheio, todos comentando que Neguinho da Mancha na Mão era uma pessoa muito boa, que apesar de fazer o que fazia, de correr atrás de uma vida de ilusões, era um ser humano dos mais raros, educado e cavalheiro. O pai de Eduarda estava indignado, falava a todo momento no ouvido de sua esposa: Um vagabundo, muié, nós quase deixamos nossa filha ficar com um vagabundo, eu nunca gostei desse cara. A mulher ouvia tudo calada, sabia que o marido também havia gostado de Neguinho, sabia que até um jogo eles haviam marcado, mas olhava o rosto de Neguinho pelo vidro do caixão $e$ achava injusto um menino tão novo estar com tantos pontos na face.

Dona Ana olhou bem de perto, e lembrou do pequeno menino que ia buscar leite para ela todas as manhãs, as moedas do troco animavam o pequeno que saía correndo pela rua em direção à padaria, lá compraria um sonho, e foi atrás disso que Neguinho da Mancha na Mão passou a vida inteira, atrás de um sonho. ${ }^{7}$

Intriga-me essa personagem sem passado e que até mesmo a fugaz memória de um momento na infância só é apresentada ao leitor a partir da lembrança guardada por

\footnotetext{
${ }^{6}$ FERRÉZ. Manual prático do ódio, p. 21.

${ }^{7}$ FERRÉZ. Manual prático do ódio, p. 239-240. (grifo nosso)
} 
Dona Ana. Em nenhum ponto da história tem-se qualquer alusão feita sobre quem e porque teria dado a ele tal apelido. Para a família de Eduarda ele era Windsor - nome dado pelo pai, segundo o próprio Neguinho, que também afirmava não saber o significado. E mesmo com todos os motivos, segundo a trama, para não ser querido por sua própria comunidade, ou melhor dizendo, ele "pertencia” à periferia, todos os que foram ao enterro simpatizavam-se com sua humanidade. Características como "educado e cavalheiro" não seriam plausíveis no mesmo "homem” que, ao matar Guile, “efetuou vários disparos e pra conferir se aproximou e deu um tiro em cada olho, estava vingada a morte de seu primo Miltinho". ${ }^{8}$ Quando a violência desmedida atinge somente aos que estão diretamente envolvidos no mundo do crime, parece haver uma tendência em minimizar ou relevar os atos cometidos por Neguinho.

No entanto, o pensamento da mãe de Eduarda, à beira do caixão de Windsor, vem revelar ao leitor o peso inigualável das linhas de comportamento sobre aquele jovem que era velado: elas não lhe pouparam nem quando é chegada a morte. Negro e morto, negro e "marcado", como se fosse essa a última oportunidade para a vida lhe diferenciar de todos os outros seres humanos, destituindo-o de vez de qualquer traço de humanidade. A representação do confronto urbano entre a vida bandida, os órgãos de segurança pública e os matadores de aluguel (“pésdepato”) surgem na derradeira cena em seu volume máximo: Windsor, transmutado em Neguinho da Mancha na Mão, termina “com tantos pontos na face”, justamente para não contrariar as estatísticas... Windsor jaz desfigurado, do mesmo modo que a personagem John Lee, criada por Gil Scott-Heron em The vulture (1996)

Continuando a seguir a trilha dessa voz narrativa afro-urbana, encontra-se no primeiro romance de Paulo Lins a associação fatal entre linhas de cor e classe. A estagnação espaço-econômico-identitária, ${ }^{9}$ presente também na peça Quando as máquinas param (1978), de Plínio Marcos, ganha em Cidade de Deus contornos extremamente dramáticos, nunca antes alcançados. O número de personagens como de Zé e Nina ${ }^{10}$ se multiplica de maneira não vista até então. Vale ainda lembrar que a

\footnotetext{
${ }^{8}$ FERRÉZ. Manual prático do ódio, p. 24.

${ }^{9}$ Expressão que aqui significa tanto formas de imobilidade geográfica (impossibilidade de se mudar para um local em melhores condições), quanto de classe (permanência numa mesma categoria de trabalho e/ou subemprego sem perspectiva de mudança) e, por fim, da categorização como grupo social: “os pobres”, “os desempregados”, “os marginais”...

${ }^{10}$ A peça de Plínio Marcos traz dois personagens - Zé e Nina - que disputam entre si o exíguo espaço de felicidade no casamento acossado pelo desemprego e, consequentemente, pela
} 
noção de “deslocamento" ${ }^{11}$ proposta no texto de Sílvia Molloy ${ }^{12}$ difere radicalmente do ocorrido para que fosse criado o espaço de Cidade de Deus (conjunto habitacional).

Esse outro “deslocamento” narrado no livro de Paulo Lins tem lugar dentro da mesma cidade e não é feito por um “Ulisses” joyceano apenas. São corpos das alteridades mais diversas, organizados em famílias - que se separaram - e bandos criminosos que se mesclam, irmanados somente pela necessidade de se sobreporem à violência de outros grupos. A “neofavela de cimento"13 é resultado desse neodeslocamento excludente, imposto por mais um "ciclo" de neomodernidade - aqui compreendida como sucessão de tentativas para preencher vácuos e/ou falhas deixadas em processos de modernização. Tanto o casal Zé e Nina, de Plínio Marcos em Quando as máquinas param, quanto a pletora de outras personagens de Paulo Lins, resistem, cada um à sua maneira, à exclusão. Resta agora mostrar um dos muitos silêncios provocados pela parada das máquinas na "neofavela”.

Ivete Walty $^{14}$ retoma a observação de que é impossível a “contenção da diversificação almejada pelo planejamento da cidade moderna”, isto é, as alteridades urbanas se mostrarão, mesmo quando excluídas. Um dos componentes principais na tentativa de obliterar o processo de retomada da visibilidade é, sem dúvida, a violência. O silêncio se impõe após os disparos que atingiram o corpo de Cabeleira:

Deitou-se bem devagar, sem sentir os movimentos que fazia, tinha uma prolixa certeza de que não sentiria a dor das balas, era uma fotografia já amarelada pelo tempo com aquele sorriso inabalável, aquela esperança da morte ser realmente um descanso para quem se viu obrigado a fazer da paz das coisas um sistemático anúncio de guerra. Aquela mudez diante das perguntas de Touro e a expressão de alegria melancólica que se manteve dentro do caixão. ${ }^{15}$

A figura de Cabeleira já denota como sua alteridade é fixada por uma característica física, uma metonímia. Longe de defini-lo, seu nome, como o de outros

escassez de recursos financeiros e oportunidades. O casal mergulha no vórtice não-solidário e o lado mais fraco, Nina, sofrerá todo o peso da violência praticada por Zé, seja psicológica e/ou física. A cena final é o ápice de todas as violências: Nina, grávida, leva um soco de seu marido justamente na barriga.

${ }^{11}$ LINS. Cidade de Deus, p. 270.

${ }^{12}$ MOLLOY. Santuários e labirintos: os lugares da memória

${ }^{13}$ LINS. Cidade de Deus, p. 17.

${ }^{14}$ WALTY. Relatos de rua - alegorias do cotidiano, p. 25.

${ }^{15}$ LINS. Cidade de Deus, p. 202. 
personagens, parecia indicar um estranho aspecto: todos eles eram superfícies de possibilidades, a vida por um fio a cada instante. O fragmento-episódio - assim denomino cada pequena história dentro de outras mais amplas - que relata o fim do marginal tem início à página 200. A denominada “paz das coisas” é transformada em prenúncio de guerra e se assemelha àquela tranquilidade que reina, momentaneamente, no "olho do furacão". Mas, similar à condição real da tempestade, as "paredes" moventes do furacão se deslocam e o centro da tormenta nunca será fixo. São essas paredes que atingem o corpo da personagem, simbolizadas pelas balas da arma do policial Touro.

O silêncio de Cabeleira diante das perguntas remete à sentença capital: "Falha a fala. Fala a bala."16 Essa sentença se transforma em mote, substituindo-se às vezes a palavra bala por lâmina. Em Cidade de Deus, as máquinas não produzem outra coisa senão “presuntos”. Ali, são elas: o revólver calibre 38, a pistola 45 automática, a escopeta calibre 12 e a metralhadora, essa última apelidada de "xereca" - um dos nomes populares atribuídos ao órgão sexual feminino - por um policial. ${ }^{17} \mathrm{~A}$ única coisa que se sobrepõe ao estrondo dessas máquinas é o choro das mães. Para Cabeleira, entretanto, o leitor fica apenas com a "mudez" tranquila que acompanha o corpo da personagem no caixão. Diferentemente de Manual prático do ódio (2003), há no texto de Paulo Lins a incômoda personagem que sobrevoa o cenário do romance de Scott-Heron: ${ }^{18}$ os abutres/urubus pululando sobre o lixo do outro lado do rio que divide a Cidade de Deus. Deixarei o abutre urbano em stand by para percorrer o texto de Conceição Evaristo.

\section{VELUDO NOS TAMANCOS...}

A voz narrativa criada pela escritora belo-horizontina, radicada no Rio de Janeiro, atravessa as tramas dos três contos num tom de inquietante serenidade. O leitor, entretanto, será chacoalhado a partir de determinado ponto da história até à derradeira palavra sem qualquer parcela de misericórdia. Nos textos “Maria”, “Ana Davenga” e “Zaita esqueceu de guardar os brinquedos” eclodiram personagens femininas, todas elas tecidas pelo tom sutil da narradora moldada por Conceição Evaristo e surpreendidas

\footnotetext{
${ }^{16}$ LINS. Cidade de Deus, p. 23.

${ }^{17}$ LINS. Cidade de Deus, p. 173.

${ }^{18}$ SCOTT-HERON. The vulture.
} 
quando ultrapassam algumas das imaginárias, mas não irreais, linhas de "cor", 19 gênero e classe. As duas primeiras personagens são adultas e sofrerão as consequências de se relacionarem, ou ter se relacionado como no caso de Maria, com homens que tiram seu sustento a partir da vida bandida. Já as principais personagens de “Zaita esqueceu...” são crianças, duas meninas, moradoras de uma das centenas de periferias espalhadas nas metrópoles...

A virulência e a crueldade que se abatem sobre Maria (a empregada doméstica que retorna para casa, após extenuante jornada de trabalho, carregando as sobras da ceia de final de ano doadas pela patroa) irá se amplificar exponencialmente para Ana Davenga. Maria sucumbirá sob o ódio dos passageiros de um ônibus que é assaltado por bandidos, dentre eles, seu antigo companheiro e pai de seu primeiro filho.

Era a primeira vez que ela via um assalto no ônibus. Imaginava o terror das pessoas. O comparsa de seu ex-homem passou por ela e não pediu nada. Se fossem outros os assaltantes? Ela teria para dar uma sacola de frutas, um osso de pernil e uma gorjeta de 35 reais. Não tinha relógio algum no braço. Nas mãos nenhum anel ou aliança. Aliás, nas mãos tinha sim! Tinha um profundo corte feito com facalaser que parecia cortar até a vida. ${ }^{20}$

A “vítima preferencial”21 possuía outro chamariz além da tripla condição de mulher, negra e pobre: o corte em sua mão talvez exalasse o sangue que atrairia os abutres e a turba ensandecida de passageiros, que poderiam ser fabulados, por sua vez, como um coletivo de hienas esfomeadas. Assim, a pequena mulher negra e pobre não teve a menor chance de defesa, foi espancada ("sangue pelos olhos, sangue pela boca, pelo nariz e pelos ouvidos”) até a morte entre as frutas que rolavam no chão do coletivo. A voz narrativa não altera um milímetro de volume, deixa que os fatos narrados se acumulem diante da visão e da consciência dos leitores... O tom de voz que narra vem encoberto por uma espécie de veludo, esse mesmo que o compositor Chico César ${ }^{22}$ desvenda ao se referir ao tecido que cobre os "tamancos" que se retiram do debate quando a voz que se enuncia é “não branca”...

A ensurdecedora delicadeza do narrar a violência, a partir desses textos de

\footnotetext{
${ }^{19}$ DU BOIS. The souls of Blakc folks.

${ }^{20}$ EVARISTO. Maria.

${ }^{21}$ DALCASTAGNÈ. Estudos de literatura brasileira contemporânea: literatura nas margens; DALCASTAGNÈ. Estudos de literatura brasileira contemporânea: a personagem do romance.
}

${ }^{22}$ CÉSAR. Respeitem meus cabelos, brancos. 
Conceição Evaristo, ressalta o mérito da voz narrativa, que faz com que o pensamento da personagem Maria se sobreponha aos grunhidos da turba que lhe ataca. Esse efeito é bastante diferente da cena de confronto entre os grupos de porto-riquenhos e os Berets nas docas da 20th Street, às margens do rio Hudson, ${ }^{23}$ que, ao ser lida, sugere os sons que eram produzidos na descrição das brigas. Para tanto, o autor se vale da escrita onomatopaica que mimetiza os estampidos de uma arma de fogo. Os fatos narrados no referido trecho de The vulture dão ainda a impressão ao leitor da rápida velocidade dos acontecimentos, naquela noite que se torna um ritual de passagem para a personagem Spade.

“Ana Davenga”, ${ }^{24}$ por sua vez, retoma de forma crítica uma constante no texto literário brasileiro canônico: mulheres negras e/ou afrodescendentes, e ainda àquelas personagens femininas denominadas “mestiças”, que por sua vez, também não geram filhos. De que modo diverso isso ocorre a partir do referido conto? O breve enredo se inicia em tom de celebração, tendo Ana em meio a uma roda de samba regada a cerveja. Todos estavam ali, menos Davenga, o chefe do bando... A narrativa percorre simultaneamente a espera de Ana e o repisar de momentos felizes que os dois tiveram. Não sem propósito, se imiscuem a tais recordações alguns flashes de violência devido à parcela criminosa vivida por Davenga. Entretanto, nem mesmo essas menções ao mundo do crime se tornam incômodos intransponíveis; Ana só tem pensamentos para seu amado.

Finalmente, ele surge em meio à euforia provocada pelos molejos do samba e dos auspícios da cerveja gelada. Todo aquele reboliço, todo aquele festejo borbulhava apenas por um motivo: o aniversário de 27 anos de Ana. Logo para ela, que nunca havia recebido um presente tão precioso naquela data. Seu aniversário, a partir dali, não seria apenas mais um dia comum.

Desaparece a trilha sonora e a ela se sobrepõe o ensurdecedor silêncio préviolência. E as paredes desse furacão atingem à Ana e ao seu homem. Alcançam ainda além, pois poucos momentos antes, o leitor é informado da gravidez dessa mulher ímpar. A humanização das personagens, em especial do bandido Davenga, coincide com a leitura feita por Clarice Lispector ${ }^{25}$ na crônica “Mineirinho”. A perplexidade da

\footnotetext{
${ }^{23}$ SCOTT-HERON. The vulture, p. 17-19.

${ }^{24}$ EVARISTO. Ana Davenga.

${ }^{25}$ LISPECTOR. Mineirinho.
} 
declaração da narradora - “É, suponho que é em mim, como um dos representantes de nós, que devo procurar por que está doendo a morte de um facínora.” ${ }^{26}$ Tanto o bandido tratado no texto de Lispector quanto aquele criado por Conceição Evaristo sucumbem justamente sob o fogo daqueles que, ao garantir a segurança dos cidadãos, devem também zelar pela integridade física do preso. E quanto à morte ficcional de Ana Davenga e seu filho ainda no ventre, que sentimento doeria nesse coletivo "nós" declarado por Clarice Lispector? A imagem derradeira do conto de Evaristo é a indagação frontal ao cânone literário brasileiro e sua prática de representação esterilizante... Principalmente quando são retratadas as personagens femininas das camadas subalternas da sociedade...

Há tempo ainda para falar de “Zaita esqueceu de guardar os brinquedos”? Não apenas por capricho cronológico esse conto finaliza este breve percurso, pois mostrouse um texto para o qual se convergiam aspectos de todos aqueles anteriormente aqui analisados. Os aspectos mais evidentes são o ambiente no qual se passa a trama (um bairro na periferia de alguma grande cidade), personagens negros e/ou afrodescendentes, a pobreza, o crime, o tráfico de drogas. Porém, os mesmos elementos podem ser encontrados em textos de autores brancos, de classe média alta... Nenhum deles, entretanto, teceu uma trama com a delicadeza e perspicácia de Conceição Evaristo. Quando o fazem, não escapam do lugar de enunciação masculino - alguns não aprenderam nem após o advento de um texto capital como A hora da estrela (1998), no qual Clarice Lispector dá uma aula magna ao criar o narrador-personagem Rodrigo S. M., expondo paradoxos do pensamento, ainda que fictício, do "macho adulto, branco, sempre no comando" 27 ... Passo a palavra à narradora elaborada por Conceição Evaristo para a apresentação do núcleo familiar de Zaita:

A mãe de Zaita estava cansada. Tinha trinta e quatro anos e quatro filhos. Os mais velhos já estavam homens. O primeiro estava no exército. Queria seguir carreira. O segundo também. As meninas vieram muito tempo depois, quando Benícia pensava que nem engravidaria mais. Entretanto, lá estavam as duas. Gêmeas. Eram iguais, iguaizinhas. A diferença estava na maneira de falar. Zaita falava baixo e lento. Naita, alto e rápido. Zaita tinha nos modos um quê de doçura, de mistérios e de sofrimento. ${ }^{28}$

\footnotetext{
${ }^{26}$ LISPECTOR. Mineirinho, p. 252.

${ }^{27}$ VELOSO. Estrangeiro.

${ }^{28}$ EVARISTO. Zaita esqueceu de guardar os brinquedos, p. 36.
} 
Fica explícita a falta de nomeação dos irmãos de Zaita, retomando o recurso utilizado por Graciliano Ramos, em Vidas secas (2002), os filhos não possuem nomes próprios (“o menino mais novo” e “o menino mais velho”). Essa metonimização possibilita algumas conjecturas: no caso dos filhos de Fabiano e Sinha Vitória uma hierarquização pela experiência, por tempo de estada naquele mundo de escassas palavras. Quanto aos filhos homens de Benícia, indicaria uma indeterminação quanto às possibilidades de futuro para ambos. De acordo com as estatísticas do local eles seriam os alvos preferenciais das balas sem ou com endereço certo: jovens negros, moradores de periferia e pobres... Outro elemento que se destaca no tocante aos irmãos é a irônica referência, feita pela narradora, às escolhas por carreiras distintas no campo militar: lutariam sob bandeiras opostas...

Já a sonoridade presente no nome de cada uma das gêmeas remete à língua árabe. Enquanto Naita seria a musicalidade agitada e aguda de algumas composições árabes, Zaita seria blues ou samba-canção. O fato de serem gêmeas idênticas, como as personagens criadas por Ana Maria Gonçalves para o romance Um defeito de cor (2006), possibilita ainda uma leitura a partir da tradição ioruba: elas são ibejis (gêmeas em ioruba). E mais importante: Zaita seria um abiku - criança nascida para morrer... O desenvolvimento e desfecho da trama praticamente ficam por conta da voz narrativa e de Naita, que se propõe a encontrar a irmã e pedir-lhe que retornasse para casa. Ela saíra e deixara de cumprir uma tarefa importante que, no entanto, permanecerá inacabada:

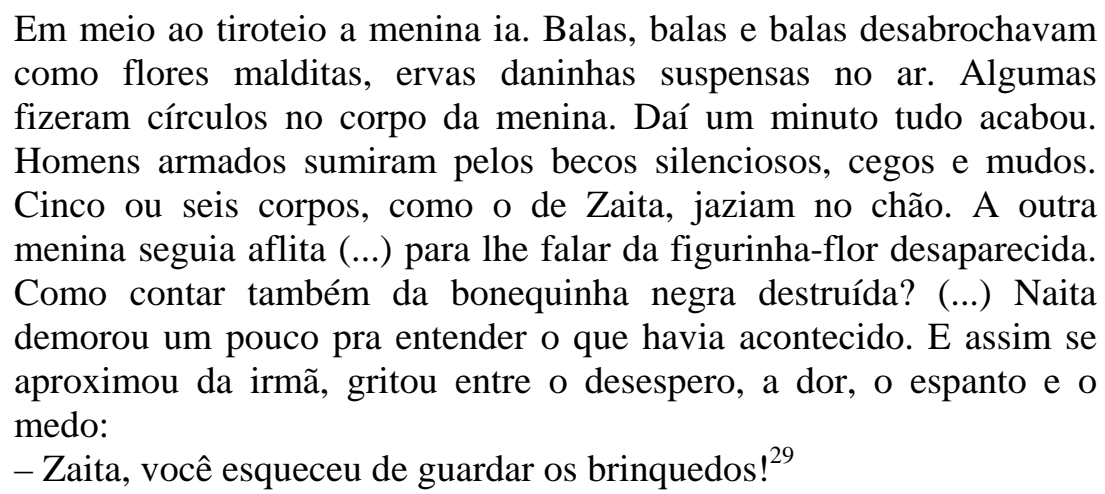

Irá o grito de Naita se sobrepor a tamanho desencanto e desperdício sob a sombra desse abominável abutre?

\footnotetext{
${ }^{29}$ EVARISTO. Zaita esqueceu de guardar os brinquedos, p. 41-42.
} 


\section{ABSTRACT}

This work aims to be a brief comparative study on Black and/or afro descendant urban literature produced from a daily contact with violence. The comparison will occur through a dialogue between The vulture, a novel by Gil Scott-Heron, and the narratives of Paulo Lins, Ferréz and Conceição Evaristo.

\section{KEYWORDS}

Afro descendant narrative, violence, representation, urban literature

\section{REFERÊNCIAS}

BOSI, Alfredo. Situação e formas do conto brasileiro contemporâneo. In: O conto brasileiro contemporâneo. 14 ed. São Paulo: Cultrix, 2002.

CÉSAR, Chico. Respeitem meus cabelos, brancos. In: brancos. Brasil: MZA/Abril Music, 2002. CD de áudio. Faixa 1.

Respeitem meus cabelos,

CRUZ, Adélcio de Sousa. Narrativas contemporâneas da violência: Fernando Bonassi, Paulo Lins e Ferréz. Belo Horizonte: UFMG - Faculdade de Letras, 2009. 228 p. Manuscrito.

DALCASTAGNÈ, Regina. Estudos de Literatura Brasileira Contemporânea: literatura nas margens, Brasília: Editora Universidade de Brasília, n. 24, jul./dez. 2004.

DALCASTAGNÈ, Regina. Estudos de Literatura Brasileira Contemporânea: a personagem do romance, Brasília: Editora Universidade de Brasília, n. 26, jul./dez. 2005.

DAVIS, Mike. Planeta favela. Trad. Beatriz Medina. São Paulo: Boitempo, 2006.

DU BOIS, W. E. B. (William Edward Burghardt). The souls of Black folks. 1903 unabridged text. Dover Publications: New York, 1994.

EVARISTO, Conceição Maria. In: QUILOMBHOJE (Org.). Cadernos Negros. São Paulo: Quilombhoje; Edição dos Autores, 1991. v. 14.

EVARISTO, Conceição Maria. Ana Davenga. In: QUILOMBHOJE (Org.). Cadernos negros: os melhores contos. São Paulo: Quilombhoje, 1998. p. 31-41.

EVARISTO, Conceição Maria. Zaita esqueceu de guardar os brinquedos. In: QUILOMBHOJE (Org.). Cadernos negros - contos afrobrasileiros. São Paulo: Quilombhoje, 2007. p. 35-42. v. 30.

FERRÉZ. Manual prático do ódio. Rio de Janeiro: Objetiva, 2003.

GILROY, Paul. The Black Atlantic: modernity and double consciousness. Cambridge, Mass.: Harvard University Press, 1993.

GONÇALVES, Ana Maria. Um defeito de cor. Rio de Janeiro, São Paulo: Record, 2006.

LINS, Paulo. Cidade de Deus. São Paulo: Companhia das Letras, 1997.

LISPECTOR, Clarice. Mineirinho. In: ___ Legião estrangeira. Rio de Janeiro: Ed. do 
Autor, 1964. p. 252-257.

LISPECTOR, Clarice A hora da estrela. Rio de Janeiro: Rocco, 1998.

MARCOS, Plínio. Quando as máquinas param. São Paulo: Global, 1978.

MOLLOY, Sylvia. Santuários e labirintos: os lugares da memória. In: Vale o escrito - a escrita autobiográfica na América Hispânica. Trad. Antônio Carlos Santos. Chapecó: Argos, 2003.

RAMOS, Graciliano. Vidas secas. 87. ed. Rio de Janeiro; São Paulo: Record, 2002.

SCOTT-HERON, Gill. The vulture. Edinburgh: Payback Press, 1996.

VELOSO, Caetano. Estrangeiro. In . Estrangeiro. Polygram, 1989. Disco de vinil.

WALTY, Ivete Lara Camargos. Relatos de rua - alegorias do cotidiano. In:

Corpus rasurado - exclusão e resistência na narrativa urbana. Belo Horizonte: Ed. Pucminas; Belo Horizonte: Autêntica, 2005. 